\title{
IMPLEMENTASI KEBIJAKAN STANDAR NASIONAL PERPUSTAKAAN PERGURUAN TINGGI: DI PERPUSTAKAAN UNIVERSITAS NEGERI MALANG
}

\author{
Bambang Santoso Haryono ${ }^{1 *}$, Teguh Yudi Cahyono ${ }^{2}$ \\ ${ }^{1}$ Fakultas Ilmu Administrasi Universitas Brawijaya \\ ${ }^{2}$ UPT Perpustakaan Universitas Negeri Malang \\ *Korespondensi: bambangsfia@ub.ac.id
}

Diajukan: 05-04-2020; Direview: 24-09-2020; Diterima: 17-10-2020; Direvisi: 01-11-2020

\begin{abstract}
The purpose of this study was to determine and describe the implementation of the National Standards for Higher Education Libraries (SNP-PT) that have been carried out by UM Library. The method used in this research is a combination of qualitative-quantitative, by observing and conducting interviews related to the implementation of the SNP-PT at the UM Library as well as using data in the form of numbers on the performance indicators of each component of the national standard. Achievement of collection indicators, UM Library have implemented 12 out of 14 collection standards for higher education libraries $(85,7 \%)$. Achievement of facilities and infrastructure indicators, UM Library have implemented 18 of 19 standard facilities and infrastructure for higher education libraries (94,7\%). Achievement of service indicators, UM Library have implemented 5 out of 5 service standards for higher education libraries (100\%). Achievement of staff indicators, UM Library have implemented 8 out of 10 staff standards for higher education libraries (80\%). Achievement of standard administration indicators, UM Library has implemented 6 out of 7 higher education library administration standards $(85,7 \%)$. Achievement of management indicators, UM Library have implemented 12 out of 12 management standards for higher education libraries (100\%). This research shows that the implementation of the SNP-PT policy has been "good" done in UM Library with an average achievement $91,01 \%$ of the standards that have been set.
\end{abstract}

\begin{abstract}
ABSTRAK
Tujuan penelitian ini adalah untuk mengetahui dan mendeskripsikan implementasi Standar Nasional Perpustakaan Perguruan Tinggi (SNP-PT) yang sudah dilakukan oleh Perpustakaan UM. Metode yang digunakan dalam penelitian ini adalah gabungan kualitatif-kuantitatif, yaitu dengan mengamati dan melakukan wawancara terkait implementasi SNP-PT pada Perpustakaan UM sekaligus menggunakan data berupa angka terhadap indikator capaian dari setiap komponen standar tersebut. Capaian indikator koleksi, Perpustakaan UM sudah mengimplementasikan 12 dari 14 standar koleksi untuk perpustakaan perguruan tinggi (85,7\%). Capaian indikator sarana dan prasarana, Perpustakaan UM sudah mengimplementasikan 18 dari 19 standar sarana dan prasarana untuk perpustakaan perguruan tinggi $(94,7 \%)$. Capaian indikator layanan, perpustakaan UM sudah mengimplementasikan 5 dari 5 standar layanan untuk perpustakaan perguruan tinggi $(100 \%)$. Capaian indikator tenaga, Perpustakaan UM sudah mengimplementasikan 8 dari 10 standar tenaga untuk perpustakaan perguruan tinggi $(80 \%)$. Capaian indikator standar penyelenggaraan, Perpustakaan UM sudah mengimplementasikan 6 dari 7 standar penyelenggaraan perpustakaan perguruan tinggi $(85,7 \%)$. Capaian indikator pengelolaan, Perpustakaan UM sudah mengimplementasikan 12 dari 12 standar pengelolaan untuk perpustakaan perguruan tinggi (100\%). Penelitian ini menunjukkan bahwa implementasi kebijakan SNP-PT sudah "baik" dilakukan pada Perpustakaan UM dengan capaian rata-rata 91,01\% dari standar yang sudah ditetapkan.
\end{abstract}

Keywords: Academic library; Higher education; Library standard; Library policy; Malang state university

\section{PENDAHULUAN}

Standar nasional untuk perpustakaan di perguruan tinggi merupakan pedoman pengelolaan perpustakaan perguruan tinggi yang ada di Indonesia sehingga terdapat kesamaan kualitas dalam mengelola perpustakaan. Standar perpustakaan perguruan tinggi dapat menjamin bahwa perpustakaan perguruan tinggi yang mengimplementasikan dapat menjadi perpustakaan dengan bermutu. Kebijakan pemerintah melalui perpustakaan nasional, telah mengeluarkan standar tersebut dengan tujuan menyeragamkan definisi, spesifikasi dan karakteristik mutu yang terdiri dari standar koleksi yang dimiliki, standar sarana-prasarana dan infrastruktur yang ada, standar 
pelayanan yang dilakukan, standar SDM pustakawan yang menjalankan, standar penyelenggaraan serta standar pengelolaan perpustakaan.

Perpustakaan perguruan tinggi harus mempunyai tujuan yang selaras dengan tujuan lembaga induknya. Untuk mencapai visi dan misi yang telah ditetapkan oleh lembaga induknya, maka perpustakaan perguruan tinggi akan memainkan peran pentingnya sebagai jantung lembaganya dalam memberikan kualitas terbaiknya untuk mendukung program kegiatan perguruan tinggi melalui berbagai layanan untuk semua pemustaka dan lingkungan sekitarnya, yaitu dengan mengumpulkan informasi dan ilmu pengetahuan, mengolah informasi, memanfaatan informasi, dan menyebarluaskan informasi.

Manajemen perpustakaan perguruan tinggi dapat menyediakan sumber informasi dan ilmu pengetahuan untuk memenuhi kebutuhan sivitas akademika sehingga program kerja dari lembaga induknya dapat tercapai sesuai dengan visi-misi yang sudah ditetapkan. Dengan dukungan perpustakaan perguruan tinggi, dapat dicapai peningkatan kinerja dan perbaikan kualitas pendidikan bagi lembaga induknya. Fungsi perpustakaan perguruan tinggi harus dioptimalkan dalam mendukung upaya tersebut. Fungsi pertama dan utama perpustakaan perguruan tinggi adalah sebagai jembatan yang memfasilitasi lembaga induknya dalam melaksanakan Tri Dharma Perguruan Tinggi, yaitu pendidikan, penelitian, dan pengabdian kepada masyarakat.

Standar untuk perpustakaan perguruan tinggi dirancang untuk pedoman perpustakaan perguruan tinggi dengan tujuan memajukan dan mempertahankan peran perpustakaan perguruan tinggi sebagai mitra dalam pendidikan, mencapai misi lembaga, dan memposisikan perpustakaan sebagai yang terdepan dalam menerapkan manajemen mutu berkelanjutan. Perpustakaan harus menunjukkan peran dan kontribusinya terhadap efektivitas kelembagaan secara keseluruhan dan bersiap dalam menghadapi perubahan dalam pendidikan tinggi. Sejak dikeluarkannya kebijakan tersebut tahun 2017, semua perpustakaan pergurun tinggi, termasuk perpustakaan Universitas Negeri Malang (UM) mulai berbenah.

Perpustakaan UM sebagai organisasi publik melakukan berbagai usaha agar menjadi perpustakaan perguruan tinggi yang berkualitas sesuai dengan standar yang berlaku. Perpustakaan UM dipilih sebagai lokasi penelitian karena memiliki sumberdaya dan fasilitas yang relatif sangat baik. Penelitian ini bertujuan untuk mengetahui capaian indikator dalam Standar Nasional Perpustakaan Perguruan Tinggi (SNP-PT) di UM, yang mengacu pada Peraturan Kepala Perpusnas Nomor 13 Tahun 2017, yaitu standar koleksi, fasilitas/sarana prasarana, pelayanan, tenaga, penyelenggaraan, dan pengelolaan perpustakaan

\section{TINJAUAN PUSTAKA}

\subsection{Implementasi Kebijakan}

Implementasi kebijakan akan terlihat setelah dikeluarkan pengarahan yang resmi dari suatu kebijakan yang meliputi upaya mengelola input untuk menghasilkan output bagi masyarakat. Implementasi kebijakan diperlukan karena ada masalah kebijakan yang perlu dilaksanakan dan dicarikan solusinya. Winarno (2014) mengatakan bahwa implementasi kebijakan adalah kegiatan yang dilakukan oleh individu atau kelompok, di lembaga pemerintah atau swasta yang diarahkan untuk mencapai tujuan-tujuan yang telah ditetapkan dalam keputusan kebijakan sebelumnya. Setelah Peraturan Kepala Perpusnas Nomor 13 Tahun 2017 disahkan, kewajiban bagi seluruh perpustakaan perguruan tinggi di wilayah Indonesia untuk melaksanakan apa yang diamanatkan dalam kebijakan tersebut. Kebijakan standarisasi untuk perpustakaan perguruan tinggi di seluruh Indonesia merupakan upaya perpustakaan nasional untuk membuat pelayanan perpustakaan perguruan tinggi memiliki kualitas yang merata. Untuk itu, dibutuhkan manajemen perpustakaan perguruan tinggi yang baik dalam mengelola sumberdaya yang dimiliki secara efektif dan efisien, agar menghasilkan output pelayanan perpustakaan perguruan tinggi yang berkualitas. 


\subsection{Standar Nasional Perpustakaan Perguruan Tinggi}

Standar merupakan kriteria untuk menetapkan dan mengevaluasi mutu dari sesuatu. Dalam hal ini, SNP-PT adalah indikator-indikator yang telah ditetapkan oleh perpustakaan nasional sebagai alat ukur untuk mengevaluasi kualitas perpustakaan perguruan tinggi di Indonesia. SNP-PT berisi indikator keberhasilan untuk mencapai mutu perpustakaan perguruan tinggi. SNP-PT meliputi standar koleksi, fasilitas, pelayanan, tenaga, penyelenggaraan, dan pengelolaan perpustakaan yang dapat memfasilitasi proses pendidikan, penelitian dan pengabdian kepada masyarakat untuk meningkatkan atmosfer akademik. Standar ini berlaku pada perpustakaan perguruan tinggi baik negeri maupun swasta yang meliputi universitas, institut, sekolah tinggi, akademi, dan politeknik (Perpusnas, 2017).

\subsection{Manajemen Perpustakaan Perguruan Tinggi}

Perpustakaan Perguruan Tinggi merupakan bagian integral dari kegiatan pendidikan, penelitian, dan pengabdian kepada masyarakat dan berfungsi sebagai pusat sumber belajar untuk mendukung tercapainya tujuan pendidikan yang berkedudukan di perguruan tinggi (Perpusnas, 2017). Perpustakaan perguruan tinggi sebagai salah satu pusat informasi harus mempunyai manajemen yang berkualitas dan terukur sehingga mampu menyediakan jasa layanan informasi secara cepat, tepat, dan akurat. Kualitas sebuah perpustakaan perguruan tinggi dapat diketahui berdasarkan standar pengelolaan perpustakaan. Semakin tinggi implementasi SNP-PT yang dilakukan oleh perpustakaan, diharapkan semakin berkualitas pula pelayanan yang dimiliki oleh perpustakaan tersebut.

\section{METODE}

Pelaksanaan penelitian ini dimulai dari bulan Januari - Maret 2020 di Perpustakaan UM. Metode yang digunakan dalam penelitian ini adalah kualitatif - kuantitatif. Fokus penelitian pada implementasi SNP-PT menurut Peraturan Kepala Perpusnas Nomor 13 Tahun 2017. Pengumpulan datanya melalui teknik dokumentasi dan wawancara mendalam. Pendokumentasian dilakukan secara deskriptif, kemudian ditabulasi dan diintepretasikan. Wawancara mendalam juga dilakukan untuk mendapatkan informasi yang benar-benar valid. Dokumentasi yang digunakan dalam penelitian ini berupa dokumen Struktur Organisasi Tata Kerja (SOTK) Perpustakaan UM, Standar Operasional Prosedur (SOP) layanan tiap unit, statistik layanan, daftar pengadaan koleksi, dan dokumen lain yang relevan dengan indikator standarisasi. Tahapan analisis data penelitian: (1) pengumpulan data; (2) kondensasi data; (3) penyajian data; dan (4) penarikan kesimpulan.

\section{HASIL DAN PEMBAHASAN}

Mengacu pada indikator SNP-PT di UM yang mencakup standar koleksi, fasilitas/sarana prasarana, pelayanan, tenaga, penyelenggaraan, dan pengelolaan perpustakaan terlihat bahwa presentase capaiannya masuk kategori tinggi yakni $91,01 \%$, yang berarti bahwa Perpustakaan UM telah berhasil memenuhi SNP-PT. Hal tersebut dapat dilihat pada Tabel 1.

Tabel 1. Presentase Capaian SNP-PT UM

\begin{tabular}{|l|c|}
\hline \multicolumn{1}{|c|}{ Indikator Standar } & Persentase (\%) \\
\hline Standar Bahan Pustaka (Koleksi) & 85,7 \\
\hline Standar Fasilitas dan Infrastruktur (Sarpras) & 94,7 \\
\hline Standar Pelayanan & 100 \\
\hline
\end{tabular}




\begin{tabular}{|l|c|}
\hline Standar Tenaga & 80 \\
\hline Standar Penyelenggaraan & 85,7 \\
\hline Standar Pengelolaan Perpustakaan & 100 \\
\hline \multicolumn{1}{|c|}{ Rata-Rata Nilai Capaian SNP-PT } & 91,01 \\
\hline
\end{tabular}

\subsection{Standar Koleksi Perpustakaan}

Manajemen perpustakaan harus dapat memberikan standar koleksi melalui kebijakan pengadaan yang dikembangkan dengan baik. Koleksi tersebut harus mendukung pengajaran dalam kurikulum dan penelitian di perguruan tinggi. Terdapat 14 indikator standar koleksi yang ditetapkan untuk perpustakaan perguruan tinggi (Tabel 2).

Tabel 2. Capaian Standar Koleksi Perpustakaan

\begin{tabular}{|c|c|c|}
\hline $\begin{array}{l}\text { Klasifikasi } \\
\text { Standar }\end{array}$ & Indikator keberhasilan & $\begin{array}{l}\text { Keteranga } \\
\text { n }\end{array}$ \\
\hline \multirow{14}{*}{$\begin{array}{l}\text { Standar } \\
\text { Koleksi }\end{array}$} & $\begin{array}{l}\text { 1. Mempunyai karya tertulis, koleksi cetak, koleksi digital atau } \\
\text { koleksi audio visual; baik fiksi maupun non fiksi }\end{array}$ & $\mathrm{Ya}$ \\
\hline & 2. Mempunyai koleksi 3 judul buku wajib tiap mata kuliah & $\mathrm{Ya}$ \\
\hline & 3. Judul buku pengembangan $2 \mathrm{x}$ jumlah buku yang diwajibkan & Ya \\
\hline & 4. Jumlah koleksi AV $2 \%$ dari total non AV & $\begin{array}{l}\mathrm{Ti} \\
\mathrm{da} \\
\mathrm{k}\end{array}$ \\
\hline & $\begin{array}{l}\text { 5. Tiap program studi dilanggankan jurnal ilmiah sebanyak } 2 \\
\text { judul }\end{array}$ & $\mathrm{Ya}$ \\
\hline & 6. Tiap program studi dilanggankan majalah minimal 1 judul & $\begin{array}{c}\mathrm{Ti} \\
\mathrm{da} \\
\mathrm{k}\end{array}$ \\
\hline & 7. Mempunyai koleksi Lokal (Skripsi, Tesis, Disertasi dll) & Ya \\
\hline & $\begin{array}{l}\text { 8. Setiap tahun mengadakan/membeli koleksi minimal } 3 \% \text { dari } \\
\text { total judul yang dimiliki }\end{array}$ & $\mathrm{Ya}$ \\
\hline & 9. Melayankan koleksi lokalnya (Skripsi, Tesis, Disertasi dll) & $\mathrm{Ya}$ \\
\hline & $\begin{array}{l}\text { 10. Menyajikan bahan pustaka Referensi minimal kamus, } \\
\text { biografi, ensiklopedi, Atlas, Direktori, dsb. }\end{array}$ & $\mathrm{Ya}$ \\
\hline & 11. Bahan pustaka diolah dengan menggunakan pedoman DDC & $\mathrm{Ya}$ \\
\hline & $\begin{array}{l}\text { 12. Melakukan cacah ulang/stok opname minimal sekali dalam } \\
\text { waktu tiga tahun, baik keseluruhan ataupun sebagian }\end{array}$ & $\mathrm{Ya}$ \\
\hline & 13. Melakukan weding/penyiangan koleksi & Ya \\
\hline & 14. Melestarikan bahan pustaka melalui penjilidan / alih media & $\mathrm{Ya}$ \\
\hline
\end{tabular}

Sumber: Perpusnas (2017)

Berdasarkan capaian indikator standar koleksi, perpustakaan UM sudah mengimplementasikan 12 standar koleksi untuk perpustakaan perguruan tinggi. Perpustakaan yang berkualitas akan memilih koleksi yang benar-benar sesuai dengan kebutuhan, minat dan selera pemustakanya. Kepuasan pemustaka akan koleksi yang disediakan oleh perpustakaan harus menjadi pertimbangan dalam proses pengadaan/pembelian bahan pustaka. Sesuai pendapat Winoto (2016), yang menyebutkan bahwa keberhasilan perpustakaan dalam memberikan layanan kepada pemustaka jika pemustaka merasa puas atas bahan pustaka yang ada di perpustakaan - karena bahan pustaka tersebut benarbenar diseleksi dengan ketat oleh pustakawan untuk kebutuhan ilmu pengetahuan dan informasi pemustaka.

Perpustakaan UM memiliki koleksi bahan pustaka dengan beragam bentuk dan tema seperti buku teks, karya tulis cetak, dan digital, baik berupa karya fiksi maupun non-fiksi sesuai dengan prodi/jurusan yang ada di lingkungan UM. Koleksi jurnal dan buku dalam bentuk digital juga tersedia di Perpustakaan UM. Untuk koleksi muatan lokal, web perpustakaan telah menyediakan akses bagi mahasiswa dan dosen untuk mengunggah secara mandiri karyanya dengan fitur yang 
mudah. Pembelian koleksi di perpustakaan UM dilakukan dengan menggunakan dana yang bersumber pada PNBP dan dana BOPTN. Untuk buku teks, perpustakaan UM mempunyai koleksi sebanyak 56.346 judul dengan jumlah eksemplar 133.797, koleksi referensi/muatan lokal yang terdiri dari Disertasi (1726), Tesis (7395) dan skripsi (49746). Jurnal nasional yang terakreditasi sebanyak 33 judul/521 eksemplar, prosiding 64 judul/88 eksemplar. Untuk jurnal yang dilanggan sebanyak 13 database/3295 judul jurnal serta ebook sebanyak 15 subyek/618 judul.

Dengan kekuatan koleksinya, khususnya koleksi digital, Perpustakaan UM dapat memberikan akses yang seluas-luasnya kepada pemustaka dan masyarakat sekitarnya. Menurut Fatmawati (2018), koleksi dalam format digital memang mempunyai kelebihan dibading dengan koleksi dengan format analog. Perpustakaan UM dapat mempublikasikan, mendistribusikan, dan menyebarluaskan koleksi digitalnya dengan cepat melalui laman web (lib.um.ac.id), misalnya mengakses e-book dan e-journal. Perpustakaan UM tidak memerlukan banyak rak untuk menempatkan ratusan jurnal dan judul bukunya, karena sebagian besar sudah dalam bentuk digital sehingga mempercepat proses layanan informasi.

Beberapa indikator standar koleksi yang belum dicapai oleh perpustakaan UM sebanyak 2 indikator. Perpustakaan UM belum memiliki jumlah koleksi audio-visual minimal 2\% dari total koleksi perpustakaan. Hal ini terkait dengan mahalnya biaya perawatan dan langkanya koleksi audio-visual yang diperjuabelikan di pasar. Daryanto (2016) menjelaskan kelemahan koleksi audiovisual diantaranya: (1) koleksi audio visual cepat rusak apabila dipakai dengan ceroboh dan anggaran perawatannya lumayan mahal; (2) membaca koleksi audio-visual lebih cepat lelah daripada membaca buku berbahan kertas; (3) membutuh operator yang ahli untuk mengoperasikan koleksi audio-visual; (4) membutuhkan hardware dan software yang dapat membaca koleksi audio visual, yang harganya mahal; dan (5) pemustaka yang meminjam koleksi audio visual juga harus mempunyai hardware dan software di rumah.

Majalah ilmiah juga menjadi faktor penghambat perpustakaan dalam menyediakan koleksinya. Informasi dan ilmu pengetahuan yang terkandung dalam jurnal sangat uptodate, sehingga kecepatan akses jurnal online menjadi pertimbangan Perpustakaan UM. Kendala berikutnya adalah prosedur stok opname dan penyiangan koleksi cetak (lama). Hal tersebut disebabkan pemanfaatan koleksi yang cukup besar oleh pemustaka sehingga menyulitkan perpustakaan melaksanakan prosedur kegiatan tersebut, terutama pada koleksi yang dipinjam oleh pemustaka dan kemudian memperpanjang waktu peminjaman.

\subsection{Standar Fasilitas Perpustakaan}

Perencanaan fasilitas perpustakaan harus dirancang dengan baik agar nyaman digunakan untuk kegiatan belajar dan akademik lainnya, dengan memperhatikan infrastruktur dan kemampuan sumber daya organisasi. Terdapat 19 indikator standar sarana dan prasarana yang ditetapkan untuk perpustakaan perguruan tinggi (Tabel 3).

Tabel 3. Capaian Standar Fasilitas Perpustakaan

\begin{tabular}{|c|c|c|}
\hline $\begin{array}{c}\text { Klasifikasi } \\
\text { Standar }\end{array}$ & Indikator keberhasilan & Ket. \\
\hline \multirow{6}{*}{ Standar Fasilitas } & $\begin{array}{l}\text { 1. Mempunyai Gedung dengan luas minimal } 0,5 \mathrm{~m} 2 \text { dari total jumlah } \\
\text { mahasiswa }\end{array}$ & Ya \\
\hline & 2. Luas ruang untuk bahan pustaka $45 \%$ dari total gedung & $\mathrm{Ya}$ \\
\hline & 3. Luas ruang untuk pengguna perpustakaan $25 \%$ dari total gedung & Ya \\
\hline & 4. Luas ruang kerja pustakawan $10 \%$ dari total gedung & Ya \\
\hline & 5. Luas area pulik/maker space $20 \%$ dari total gedung & Ya \\
\hline & $\begin{array}{l}\text { 6. Ruang serial dan media massa memiliki pencahayaan minimal } 200 \\
\text { lumen }\end{array}$ & Ya \\
\hline
\end{tabular}




\begin{tabular}{|l|l|c|}
\hline 7. Ruang baca memiliki pencahayaan minimal 400 lumen & Ya \\
\hline 8. Ruang rujukan memiliki pencahayaan minimal 600 lumen & Ya \\
\hline 9. Ruang peminjaman memiliki pencahayaan minimal 600 lumen & Ya \\
\hline 10. Ruang pengolahan memiliki pencahayaan minimal 400 lumen & Ya \\
\hline 11. Gudang memiliki pencahayaan minimal 100 lumen & Ya \\
\hline 12. Ruang rak buku memiliki pencahayaan minimal 200 lumen & Ya \\
\hline 13. Ruang kerja memiliki pencahayaan minimal 400 lumen & Ya \\
\hline 14. Ruang audio visual memiliki pencahayaan minimal 100 lumen & Ya \\
\hline 15. Kelembaban di ruang rak buku 45 - 55 rh & Ya \\
\hline 16. Kelembaban di ruang audio visual 20 - 21 rh & Ya \\
\hline 17. Suhu ruangan baca, rak koleki dan tempat kerja $20^{\circ} \mathrm{C}-25^{\circ} \mathrm{C}$ & Ya \\
\hline 18. Mempunyai fasilitas ruang untuk pemustaka difabel & Tidak \\
\hline 19. Lokasi Perpustakaan di tengah-tengah area kampus & Ya \\
\hline
\end{tabular}

Sumber: Perpusnas (2017)

Berdasarkan capaian indikator standar sarana dan prasarana, perpustakaan UM sudah mengimplementasikan 18 standar fasilitas untuk perpustakaan perguruan tinggi. Perpustakaan UM berada di tengah-tengah kampus, luas lahan perpustakaan UM adalah 5.340 meter persegi, dengan gedung megah berlantai tiga. Sebagaimana yang dikatakan Imamah (2017), bahwa lokasi perpustakaan idealnya berada di pusat kampus sehingga mudah dijangkau oleh mahasiswa, dosen dan tenaga pendidik. Dengan jumlah mahasiswa 33.638 orang, maka luas gedung perpustakaan UM masuk dalam kategori memenuhi standar, karena lahannya luas dan terdiri dari gedung berlantai tiga.

Penempatan koleksi pada perpustakaan terdapat di lantai dua (koleksi nomor DDC 000-574), dan untuk koleksi dengan nomor DDC (575-900) berada di lantai 3. Di setiap unit layanan juga terdapat area/rak koleksi masing-masing. Pada layanan sirkulasi, terdapat juga area/rak koleksi untuk penitipan buku yang akan dipinjam oleh pemustaka. Pada layanan jurnal dan majalah, juga terdapat area/rak koleksi dan lemari koleksi untuk majalah dan jurnal yang baru. Pada layanan reserve, layanan koleksi lokal (disertasi, tesis, dan skripsi) juga terdapat area/rak koleksi yang relatif luas. Konsekuensinya adalah perpustakaan perlu menyediakan area baca/santai yang luas bagi pemustaka. Hampir di semua lantai, terdapat area pemustaka yang sangat luas. Perpustakaan UM juga menyediakan area publik, seperti mushola (dua lokasi), toilet di setiap lantai, kafe yang representative dan juga selasar ruangan yang biasa digunakan oleh pemustaka untuk belajar, pentas seni dan musik, bazar buku, dsb. Lasa (2016) mengatakan bahwa bangunan perpustakaan memiliki sub-sistem dan fungsi yang berbeda-beda. Untuk merencanakan interior dan eksterior gedung/ruang perpustakaan, dapat memperhatikan fungsi, keharmonisan serta keindahan ruang tersebut.

Menurut Mumpuni (2017) berdasarkan standar nasional, pencahayaan suatu ruangan minimum mempunyai ukuran 300lux. Dengan luxmeter, pencahayaan di perpustakaan UM melebihi standar, karena mempunyai pencahayaan yang terang (dengan rata-rata 1000lux tiap ruangannya). Untuk pencahayaan, selain menggunakan lampu yang cukup banyak dan terang, setiap dinding bangunan perpustakaan UM terdapat jendela kaca yang besar. Sehingga dapat membantu pencahayaan ruang perpustakaan dengan sangat baik. Pencahayaan alami yang berasal dari sinar matahari, selain menambah terang ruangan dan menghemat energi, sinar matahari juga menyehatkan karena dapat membunuh kuman. Perpustakaan UM mempunyai ruang audio visual layaknya gedung bisokop agar pemustaka bisa merasa nyaman dalam memanfaatkan koleksi audiovisual yang dimiliki perpustakaan UM.

Indikator standar fasilitas perpustakaan yang belum terpenuhi di Perpustakaan UM adalah ruang belajar atau membaca untuk pemustaka difabel (yang berkebutuhan khusus) belum tersedia 
di perpustakaan UM. Mereka harus belajar dan membaca di ruangan yang sama dengan pemustaka normal lainnya. Mereka hanya akses masuk ke pintu utama perpustakaan yang sudah dibuat jalan untuk pemustaka berkebutuhan khusus, kemudian menunggu di lantai satu hingga menunggu petugas perpustakaan untuk mendapatkan bantuan pencarian informasi dan peminjaman koleksi.

\subsection{Standar Pelayanan Perpustakaan}

Layanan perpustakaan perguruan tinggi yang efektif dan berkualitas tinggi dapat mendukung visi dan misi lembaga induknya. Layanan perpustakaan harus memberikan akses ke berbagai sumber daya informasi. Layanan perpustakaan perguruan tinggi adalah laboratorium bagi sivitas akademik untuk memperoleh keterampilan literasi informasi dengan mengidentifikasi informasi, serta menggunakan sumber daya secara efektif, efisien dan etis. Terdapat 5 indikator standar pelayanan yang ditetapkan untuk perpustakaan perguruan tinggi (Tabel 4).

Tabel 4. Capaian Standar Pelayanan Perpustakaan

\begin{tabular}{|c|c|c|}
\hline $\begin{array}{c}\text { Klasifikasi } \\
\text { Standar }\end{array}$ & Indikator Keberhasilan & Ket. \\
\hline \multirow{5}{*}{$\begin{array}{c}\text { Standar } \\
\text { Pelayanan }\end{array}$} & 1. Perpustakaan membuka jam layanan 54 jam tiap minggu & $\mathrm{Ya}$ \\
\hline & 2. Mempunyai layanan sirkulasi, referensi, dan literasi informasi & Ya \\
\hline & 3. Perpustakaan mempunyai laporan statistik untuk setiap unit layanan & Ya \\
\hline & $\begin{array}{l}\text { 4. Melakukan pengembangan melalui kerjasama dengan } \\
\text { perpustakaan/organisasi lain }\end{array}$ & $\mathrm{Ya}$ \\
\hline & 5. Melakukan promosi perpustakaan & Ya \\
\hline
\end{tabular}

Sumber: Perpusnas (2017)

Berdasarkan capaian indikator standar layanan, Perpustakaan UM sudah mengimplementasikan semua standar layanan untuk perpustakaan perguruan tinggi. Menurut Muniarti (2013), jam buka layanan perpustakaan adalah ketika layanan perpustakaan dibuka yang dilakukan oleh petugas perpustakaan kepada pemustaka, maupun dibukanya semua fasilitas dan koleksi perpustakaan untuk pemustaka yang dating. Jam buka layanan perpustakaan UM untuk hari senin sampai dengan hari jumat dimulai dari jam 7 pagi hingga jam 7 malam, tanpa menutup layanan untuk istirahat. Strategi layanannya adalah sebagai berikut. Pada saat jam istirahat, petugas perpustakaan akan bergiliran, sebagian beristirahat, sebagian masih melakukan proses layanan. Waktu istirahat yang dialokasikan untuk setiap petugas perpustakaan adalah lebih kurang satu jam, cukup untuk melakukan ishoma dan mengembalikan kebugaran dalam bekerja. Pada hari sabtu perpustakaan UM buka dari jam 8 pagi hingga jam 2 siang, juga tanpa jeda istirahat layanan. Jadi dalam seminggu jam buka perpustakaan sekitar 66 jam, melebihi standar minimal jam buka sebesar 54 jam kerja per minggu.

Menurut Ulpiatiah (2017), ada dua kategori layanan perpustakaan, yaitu layanan langsung dan layanan tidak langsung. Layanan langsung meliputi layanan sirkulasi, layanan referensi, dan pelayanan literasi untuk pemustaka. Pemustaka juga dapat mengakses layanan mandiri melalui Handphone, mereka dapat mengakses layanan mandiri tersebut. Apabila sudah yakin dengan bahan pustaka yang dimaksud, barulah pemustaka datang untuk melakukan transaksi peminjaman di perpustakaan UM. Petugas hanya melakukan verifikasi setelah pemustaka melakukan transaksi peminjaman mandiri, apakah sudah berhasil prosesnya ataukah gagal? Perpustakaan UM juga menyediakan layanan rujukan dan penelusuran informasi bagi pemustaka. Layanan tersebut dikenal dengan layanan referensi. Layanan referensi melayani peminjaman karya ilmiah tugas akhir, skripsi, tesis, disertasi, dan laporan penelitian. Koleksi karya ilmiah hanya terbatas satu eksemplar, sehingga pemustaka hanya boleh membaca di tempat atau fotokopi. Perpustakaan UM juga mengembangkan layanan karya ilmiah dosen dalam bentuk digital. Layanan ini disebut layanan 
ETD (Electronic Thesis and Disertation). Layanan lainnya adalah layanan literasi untuk membantu pemustaka menemukan koleksi dan sumber informasi yang dibutuhkannya.

Maryono (2015) menjelaskan data statistik merupakan data yang dicatat, dalam bentuk tabel, yang menginformasikan fakta, kemudian dapat diarsipkan dan ditelusuri kembali untuk tujuan pengambilan keputusan. Setiap unit layanan perpustakaan UM wajib membuat laporan statistik harian, bulanan dan tahunan sesuai dengan program kerja lembaga. Data statistik dari masingmasing unit layanan tersebut kemudian dijadikan satu sebagai bahan pertimbangan kepala perpustakaan mengambil kebijakan atau pun menentukan program kerja perpustakaan ke depan. Kerjasama perpustakaan UM diwujudkan melalui FKP2TN yang beranggotakan 72 PTN di Jawa, Bali, Sumatra, Sulawesi dan Bali. Saat ini Perpustakaan UM menjadi salah satu pengurus FKP2TN. Perpustakaan UM berpartsisipasi sebagai salah satu kontributor portal Indonesia One-Search yang dikembangkan oleh Perpustakaan Nasional. Perpustakaan UM telah mengirimkan sebanyak lebih kurang 56.000 file indikatif (berisi data skripsi, tesis, dan disertasi) sebagian besar dilengkapi abstrak, dan informasi indikatif dalam bentuk katalog. Hal tersebut sejalan dengan Pasal 42 UU No.43/2007 tentang Perpustakaan bahwa untuk meningkatkan layanan kepada pemustaka, perpustakaan perguruan tinggi dapat bekerjasama dengan berbagai pihak. Peningkatan kerjasama ini bertujuan untuk menambah jumlah pemustaka dan meningkatkan mutu layanan. Promosi Perpustakaan UM dilakukan melalui media sosial, website perpustakaan, dan dalam kegiatan pendidikan pemustaka tiap awal tahun ajaran baru.

\subsection{Standar Tenaga Perpustakaan}

Untuk tenaga perpustakaan, Perpustakaan UM telah memiliki SDM yang memadai, baik dari segi jumlah maupun kualitas, untuk memastikan keunggulan dan kemajuan layanan perpustakaan. Ada 10 indikator standar tenaga perpustakaan perguruan tinggi (Tabel 5).

Tabel 5. Capaian Standar Tenaga Perpustakaan

\begin{tabular}{|c|c|c|}
\hline $\begin{array}{c}\text { Klasifikasi } \\
\text { Standar }\end{array}$ & Indikator Keberhasilan & Ket. \\
\hline \multirow{10}{*}{$\begin{array}{c}\text { Standar Tenaga } \\
\text { Perpustakaan }\end{array}$} & $\begin{array}{l}\text { 1. Mempunyai SDM perpustakaan yaitu pustakawan, staf administrasi } \\
\text { dan kepala perpustakaan }\end{array}$ & $\mathrm{Ya}$ \\
\hline & 2. Perpustakaan dikelola sekurang-kurangnya oleh 2 pustakawan & $\mathrm{Ya}$ \\
\hline & 3. Kepala perpustakaan di bawah koordinasi pimpinan lembaga induk & $\mathrm{Ya}$ \\
\hline & $\begin{array}{l}\text { 4. Pendidikan kepala perpustakaan minimal magister atau pernah } \\
\text { mengikuti diklat perpustakaan }\end{array}$ & $\mathrm{Ya}$ \\
\hline & $\begin{array}{l}\text { 5. Kepala perpustakaan mempunyai sertifikat dari perpustakaan } \\
\text { nasional }\end{array}$ & Tidak \\
\hline & 6. Pengangkatan kepala perpustakaan berdasarkan SK Rektor & $\mathrm{Ya}$ \\
\hline & $\begin{array}{l}\text { 7. Kualifikasi Pustakawan minimal S-1 dan staf administrasi } \\
\text { sekurangnya berpendidikan D-3 }\end{array}$ & $\mathrm{Ya}$ \\
\hline & 8. Perbandingan jumlah pustakawan dan mahasiswa 1: 500 & Tidak \\
\hline & 8. Perbandingan jumlah staf administrasi dan mahasiswa 1: 5000 & $\mathrm{Ya}$ \\
\hline & 10. Mengembangkan SDM melalui pendidikan formal dan non formal & $\mathrm{Ya}$ \\
\hline
\end{tabular}
Sumber: Perpusnas (2017)

Berdasarkan capaian indikator standar tenaga, Perpustakaan UM sudah mengimplementasikan 8 standar tenaga perpustakaan perguruan tinggi. Jumlah tenaga Perpustakaan UM sebanyak 34 orang staf, yang terdiri dari 12 orang dengan status pustakawan, 15 orang staf adminsitrasi, dan tenaga harian sebanyak 7 orang. Pustakawan UM tersebar di beberapa unit layanan langsung maupun layanan tidak langsung. Pustakawan di bagian pengolahan bertugas menyeleksi, mengolah, dan menyajikan bahan pustaka di rak koleksi Perpustakaan UM. Pustakawan di bagian serial bertugas memberikan pelayanan jurnal, majalah, dan surat kabar untuk pemustaka. Pustakawan di bagian 
referensi bertugas menyajikan layanan koleksi lokal dan koleksi rujukan bagi pemustaka. Pustakawan di bagian sirkulasi bertugas memberikan layanan sirkulasi bahan pustaka, meliputi transaksi peminjaman, pengembalian, dan perpanjangan waktu kembali untuk bahan pustaka yang masih dibutuhkan oleh pemustaka.

Selain pustakawan, juga ada staf administrasi Perpustakaan UM yang bertugas membantu beberapa tugas pekerjaan di perpustakaan. Staf administrasi dapat membantu pelayanan pendaftaran anggota dari Pemustaka UM dan lingkungan sekitar. Kualitas dan jumlah staf perpustakaan perlu dikelola dengan baik, melalui mekanisme analisis beban kerja, dan peta jabatan organisasi perpustakaan UM sehingga dicapai kebutuhan ideal staf perpustakaan. Pembinaan SDM perpustakaan dilakukan secara terus menerus. Untuk meningkatkan kompetensi pustakawan, perpustakaan memberikan kesempatan kepada staf untuk mengikuti pendidikan formal S2 (4 orang), memberikan kesempatan untuk mengikuti pendidikan S1- Ilmu Perpustakaan (4 orang), dan mengikutsertakan pustakawan dalam berbagai seminar dan lokakarya nasional bidang kepustakawanan.

Dalam PP 24/2014 dinyatakan bahwa perpustakaan dipimpin oleh seorang kepala perpustakaan, kecuali memang dalam sebuah institusi belum ada yang memenuhi syarat untuk jabatan tersebut. Terdapat keunikan mengenai Kepala Perpustakaan UM (Prof. Djoko Saryono MPd.), di mana beliau tidak memiliki pendidikan dan pelatihan perpustakaan secara formal, namun pemahaman dan pengalamannya dalam bidang kepustakawanan sangat luar biasa. Meskipun ahli di bidang bahasa dan sastra Indonesia, beliau sangat memahami tentang memajukan Perpustakaan UM di masa depan. Kepala Perpustakaan UM sangat aktif menjadi pembicara dalam acara seminar perpustakaan yang diadakan oleh perguruan tinggi atau organisasi perpustakaan lainnya. Banyak program kerja perustakaan yang menjadi acuan kemajuan Perpustakaan UM, diantaranya penguatan SDM dan koleksi digital, pemanfaatan TIK melalui media sosial perpustakaan, dan membuka ruang belajar yang nyaman bagi pemustaka (seperti melalui beringin baca, kafe pustaka, dan taman belajar).

\subsection{Standar Penyelenggaraan Perpustakaan}

Penyelenggaraan perpustakaan yang efektif dapat memberikan pengalaman yang mudah, dan produktif kepada pemustaka untuk memanfaatkan perpustakaan. Hal ini sesuai dengan fungsi perpustakaan sebagai sumber belajar yang menyediakan akses seluas-luasnya terhadap ilmu pengetahuan dan informasi. Terdapat 7 indikator standar penyelenggaraan perpustakaan perguruan tinggi (Tabel 6).

Tabel 6. Capaian Standar Penyelenggaraan Perpustakaan

\begin{tabular}{|c|c|c|}
\hline $\begin{array}{l}\text { Klasifikasi } \\
\text { Standar }\end{array}$ & Indikator Keberhasilan & Ket. \\
\hline \multirow{7}{*}{$\begin{array}{l}\text { Standar } \\
\text { Penyelenggaraan }\end{array}$} & 1. Berdirinya perpustakaan ditetapkan dengan SK Rektor & $\mathrm{Ya}$ \\
\hline & 2. Mempunyai nomor pokok perpustakaan (terdaftar di Perpusnas) & $\mathrm{Ya}$ \\
\hline & $\begin{array}{l}\text { 3. Organisasi perpustakaan terdiri dari kepala, unit layanan, unit teknis, } \\
\text { unit TIK dan tata usaha }\end{array}$ & $\mathrm{Ya}$ \\
\hline & $\begin{array}{l}\text { 4. Perpustakaan bukan sebagai unit pelaksana teknis, tetapi adalah sub } \\
\text { sistem dari sistem pendidikan }\end{array}$ & Tidak \\
\hline & 5. Kepala perpustakaan menjadi anggota senat perguruan tinggi & $\mathrm{Ya}$ \\
\hline & $\begin{array}{l}\text { 6. SOTK perpustakaan minimial terdiri dari rektor, kepala perpus, tata } \\
\text { usaha, unit teknis, unit layanan dan unit TIK }\end{array}$ & $\mathrm{Ya}$ \\
\hline & 7. Perpustakaan memiliki program kerja yang berkelanjutan & Ya \\
\hline
\end{tabular}


Berdasarkan capaian indikator standar penyelenggaraan, Perpustakaan UM sudah mengimplementasikan 6 standar penyelenggaraan perpustakaan perguruan tinggi. Sesuai dengan perkembangan, jenis dan bentuk layanan serta peningkatan pemanfaatan teknologi informasi maka struktur organisasi Perpustakaan UM dapat dikembangkan sesuai dengan kebutuhan.

Hal tersebut sesuai dengan Pasal 34 Peraturan Pemerintah Nomor 30/1990 yang menyebutkan bahwa perpustakaan pendidikan/perguruan tinggi merupakan unit pelaksana teknis. Begitu pula dengan perpustakaan UM, yang mendukung kegiatan pendidikan, penelitian dan pengabdian kepada masyarakat. Kepala perpustakaan UM bertanggungjawab langsung kepada rektor (wakil rektor akademik dan umum). Struktur organisasi dan tata kerja Perpustakaan UM mengacu pada SK Rektor IKIP Malang Nomor: 0243/KEP/PT.28.H/O/99, tanggal 4 Agustus 1999 tentang pendirian IKIP Malang atau Universitas Negeri Malang (UM).

Beberapa program kerja perpustakaan UM adalah peningkatan infrastruktur dan fasilitas fisik, pengembangan sosio-kultural dan akademis, pembenahan aspek manajerial melalui penguatan SDM, akreditasi perpustakaan, dan ikut berperan aktif dalam organisasi perpustakaan dan akademik. Pada tahun 2020, perpustakaan mengajukan proses akreditasi ke perpustakaan nasional, sehingga kualitas perpustakaan UM akan mendapat jaminan secara nasional. Sebagai UPT, perpustakaan melaksanakan tugas teknis operasional untuk menunjang tercapainya misi lembaga induknya. Perpustakaan UM mempunyai kewenangan mengelola kepegawaian, keuangan, dan perlengkapan organisasinya secara mandiri.

\subsection{Standar Pengelolaan Perpustakaan}

Manajemen perpustakaan akan terlibat dalam pengambilan keputusan untuk mengoptimalkan alokasi sumber daya dalam mencapai visi dan misi perpustakaan secara efektif dan efisien. Terdapat 12 indikator standar pengelolaan yang ditetapkan untuk perpustakaan perguruan tinggi (Tabel 7).

Tabel 7. Capaian Standar Pengelolaan Perpustakaan

\begin{tabular}{|c|c|c|}
\hline $\begin{array}{l}\text { Klasifikasi } \\
\text { Standar }\end{array}$ & Indikator keberhasilan & Ket. \\
\hline \multirow{12}{*}{$\begin{array}{c}\text { Standar } \\
\text { Pengelolaan }\end{array}$} & $\begin{array}{l}\text { 1. Perpustakaan mempunyai visi, misi dan rencana strategis secara } \\
\text { tertulis dan disahkan oleh Rektor }\end{array}$ & $\mathrm{Ya}$ \\
\hline & 2. Perpustakaan mempunyai visi yang sejalan dengan visi lembaganya & $\mathrm{Ya}$ \\
\hline & $\begin{array}{l}\text { 3. Perpustakaan mempunyai misi yang menopang kegiatan } \\
\text { akademik lembaganya }\end{array}$ & $\mathrm{Ya}$ \\
\hline & $\begin{array}{l}\text { 4. Perpustakaan menjadi sumber belajar yang menyediakan bahan } \\
\text { pustaka dan akses informasi untuk mencapai tri dharma lembaganya }\end{array}$ & Ya \\
\hline & $\begin{array}{l}\text { 5. Koleksi perpustakaan dikembangkan, dikelola dan dimanfaatkan } \\
\text { untuk memenuhi kebutuhan pemustaka }\end{array}$ & Ya \\
\hline & 6. Perpustakaan mencukupi kebutuhan literasi pemustaka & $\mathrm{Ya}$ \\
\hline & 7. Memanfaatkan TIK dalam mengembangkan sistem layanan & $\mathrm{Ya}$ \\
\hline & 8. Perpustakaan melakukan pelestarian isi dan media bahan pustaka & $\mathrm{Ya}$ \\
\hline & $\begin{array}{l}\text { 9. Perpustakaan selalu menopang kebijakan lembaganya untuk } \\
\text { mencapai tujuan tridharma }\end{array}$ & Ya \\
\hline & $\begin{array}{l}\text { 10. Perpustakaan memiliki fungsi pendidikan, informasi, penelitian, } \\
\text { relaksasi, publikasi, deposit serta interpretasi informasi dan iptek }\end{array}$ & $\mathrm{Ya}$ \\
\hline & 11. Pagu anggaran perpustakaan minimal 5\% dari lembaganya & Ya \\
\hline & 12. Perpustakaan menggunakan TIK dalam proses layanan pemustaka & $\mathrm{Ya}$ \\
\hline
\end{tabular}
Sumber: Perpusnas (2017)

Berdasarkan capaian indikator standar pengelolaan, Perpustakaan UM sudah mengimplementasikan semua standar pengelolaan untuk perpustakaan perguruan tinggi. Pengelolaan perpustakaan dimulai dengan merumuskan visi, misi, dan tujuan perpustakaan yang 
disesuaikan dengan lembaga induknya, agar rangkaian program kerja yang dijalankan oleh perpustakaan lebih terarah untuk menopang tujuan visi misi lembaga induknya.

Visi merupakan sesuatu yang filosofis, idealis, dan realistis. Visi merupakan cita-cita untuk mencaai tujuan ideal organisasi. Pengesahan visi misi perpustakaan UM didasarkan pada surat Keputusan Rektor Universitas Negeri Malang Nomor 9 Tahun 2019 tentang Rencana Strategis Bisnis Universitas Negeri Malang. Visi UPT Perpustakaan UM adalah mewujudkan UPT Perpustakaan UM sebagai pusat rujukan informasi ilmiah (information center) dan center of knowledge access dalam mendukung Tridharma Perguruan Tinggi, berorientasi memenuhi kebutuhan pembangunan, masyarakat, dan kemanusiaan dengan memperhatikan wawasan lokal, nasional, regional, dan global. Hal ini sangat mendukung visi lembaga UM untuk menjadi perguruan tinggi unggul dan menjadi rujukan ilmu pengetahuan, teknologi dalam bidang kependidikan.

Sedangkan, misi adalah penjabaran kegiatan dalam program kerja yang harus didijalankan agar lebih realistis dalam mencapai visi organisasi. Misi UPT Perpustakaan UM yaitu: (a) melakukan layanan peminjaman, referensi dan penelusuran informasi menggunakan TIK untuk sivitas akademika, berprinsip kemudahan prosedur serta keterbaruan informasi untuk menunjang kegiatan Tridharma di lingkungan UM; (b) melakukan penguatan koleksi perpustakaan sesuai dengan perkembangan ilmu pengetahuan dan teknologi, serta melakukan melayani penelusuran informasi lewat dukungan TIK; (c) menyebarluaskan informasi tentang koleksi terbaru dengan berbasis TIK; (d) Mengembangkan sistem layanan perpustakaan dan tenaga; dan (e) melakukan kerjasama untuk meningkatkan dan mempermudah akses sumber informasi.

Pengembangan perpustakaan UM ke depan yaitu mencapai visi misi UM dan menjadi bagian penting dari kegiatan tri dharma perguruan tinggi. Perpustakaan UM mempunyai garis besar organisasi dalam mewujudkan life based learning. Perpustakaan UM akan menjadi sumber belajar yang terbuka bagi sivitas akademik dan lingkungan sekitar, menjadi perpustakaan akademik yang menopang kegiatan akademik lembaga, menjadi perpustakaan digital karena perkembangan teknologi dan informasi telah membingkai aktifitas semua organisasi termasuk perpustakaan, serta menajadi perpustakaan ekologis sehingga pemustaka betah belajar dengan lingkungan yang nyaman sebagai salah satu tempat relaksasi. Beberapa program kerja perpustakaan adalah peningkatan infrastruktur dan fasilitas fisik, pengembangan sosio-kultural dan akademis, pembenahan aspek manajerial melalui penguatan SDM, akreditasi perpustakaan, dan ikut berperan aktif dalam organisasi perpustakaan dan akademik. Diantaranya adalah melalui kerjasama dengan Scopus dan perpustakaan nasional untuk memperkaya bahan pustaka. Perpustakaan UM juga akan melipatgandakan anggaran untuk pengadaan koleksi ilmiah dalam bentuk elektronik dan alihmedia koleksi local, seperti skripsi, tesis, disertasi, dsb.

\section{KESIMPULAN}

Implementasi standar koleksi pada perpustakaan UM mencapai 85,7\% dari indikator yang ditetapkan dalam SNP-PT. Koleksi perpustakaan yang kuat akan mendukung pengajaran dalam kurikulum dan penelitian di perguruan tinggi, melalui kebijakan pengadaan yang dikembangkan dengan baik. Implementasi standar sarana dan prasarana pada perpustakaan UM mencapai 94,7\% dari indikator yang ditetapkan dalam SNP-PT. Fasilitas dan infrastruktur perpustakaan harus memadai dan fungsional. kondusif untuk belajar dan kegiatan akademik lainnya. Implementasi standar layanan pada Perpustakaan UM mencapai 100\% dari indikator yang ditetapkan dalam SNPPT. Layanan perpustakaan perguruan tinggi yang efektif dan berkualitas tinggi dapat mendukung program kerja lembaga induknya. Sebagai fasilitas keberhasilan akademik, layanan perpustakaan harus memberikan akses ke berbagai sumber daya informasi. Implementasi standar tenaga Perpustakaan UM mencapai $80 \%$ dari indikator yang ditetapkan dalam SNP-PT. Sejak dini 
perpustakaan harus menyiapkan jumlah dan kualitas tenaga yang memadai untuk memastikan keunggulan dan kemajuannya dalam lingkungan yang terus berubah. Implementasi standar penyelenggaraan pada Perpustakaan UM mencapai 85,7\% dari indikator yang ditetapkan dalam SNP-PT. Penyelenggaraan perpustakaan yang efektif dapat memenuhi kebutuhan informasi dan penelitian, serta mendukung pembelajaran pemustaka, dengan memberikan pengalaman yang mudah, dan produktif kepada pemustaka untuk memanfaatkan perpustakaan. Implementasi standar pengelolaan pada Perpustakaan UM mencapai $100 \%$ dari indikator yang ditetapkan dalam SNPPT. Manajemen perpustakaan berhasil mengambil keputusan untuk mengoptimalkan sumber daya, sehingga dapat mencapai visi dan misi perpustakaan secara efektif dan efisien. Penelitian ini menunjukkan bahwa implementasi SNP-PT pada Perpustakaan UM mencapai 91,01\% dari standar yang sudah ditetapkan.

\section{DAFTAR PUSTAKA}

Bando, M.S., et.al. 2014. Standar Nasional Perpustakaan Perguruan Tinggi. Jakarta: Perpustakaan Nasional RI.

Budi, W. 2014. Kebijakan Publik: Teori, Proses, dan Studi Kasus. Yogyakarta: Center of Academic Publishing Service.

Daryanto, D. 2016. Media Pembelajaran. Yogyakarta: Gava Media.

Fatmawati, E. 2018. Preservasi, Konservasi, dan Restorasi Bahan Perpustakaan Universitas Diponegoro. Jurnal Libria, 10(1).

Hardiyansyah, H. 2017. Manajemen Pelayanan dan Pengembangan Organisasi Publik dalam Perspektif Riset Ilmu Administrasi Publik Kontemporer. Yogyakarta: Gava Media.

Higgins, S. 2017. Managing Academic Libraries Principles and Practice. UK: Elsevier.

Imamah, F.N. 2017. Penerapan Standar Nasional Perpustakaan Perguruan Tinggi (SNP010:2011) di Perpustakaan Universitas Muhammadiyah Makassar. Tesis. Makassar: UIN Alauddin.

Larasati, R., et.al. 2018. Analisis Penerapan Good University Governance pada Perguruan Tinggi di Kota Jayapura. Journal of Applied Managerial Accounting, 2(2), 304-323.

Lasa, HS. 2016. Manajemen Perpustakaan. Yogyakarta: Ombak.

Maryono, M. 2015. Statistik Perpustakaan dan Kualitas Informasinya. Yogyakarta: Universitas Gadjah Mada.

Mumpuni, P.W. 2017. Pencahayaan Alami pada Ruang Baca Perpustakaan Umum Kota Surabaya. Jurnal Arsitektur, Bangunan, \& Lingkungan, 6(2), 71-78.

Munde, G., et.al. 2009. Surviving the Future Academic Libraries, Quality, and Assessment. Oxford: Chandos Publishing.

Muniarti, M. 2013. Pengaruh Jam Buka Pelayanan Perpustakaan terhadap Minat Kunjung Pemustaka di KPAD Kabupaten Gunung Kidul. Skripsi.Yogyakarta: UIN Sunan Kalijaga.

Musdalipa, M. 2017. Kepemimpinan Kepala Perpustakaan Terhadap Kinerja Karyawan di UPT Perpustakaan UIN Alauddin Makassar. Skripsi. Makassar: UIN Alauddin.

Nor, G. 2014. Manajemen Publik pada Pemerintahan. Jakarta: Bumi Angkasa.

Peraturan Kepala Perpustakaan Nasional Republik Indonesia Nomor 13 Tahun 2017 tentang Standar Nasional Perpustakaan Perguruan Tinggi. Jakarta. 
Simanjuntak, M.R. 2014. Analisis Sistem Manajemen Mutu dan Pengaruhnya dalam Meningkatkan Kinerja Operasional Bangunan Gedung Tinggi Perkantoran di Jakarta Pusat. Jurnal Ilmiah Media Engineering, 4(2), 92-102.

Sirajuddin, I.A. 2014. Implementasi Kebijakan Pemerintah Daerah dalam Pelayanan Publik Dasar Bidang Sosial di Kota Makassar. Jurnal Administrasi Publik, 4(1).

Suwarno, W. 2010. Pengetahuan Dasar Kepustakaan: Sisi Penting Perpustakaan dan Pustakawan. Bogor: Ghalia Indonesia.

Umar, U. 2017. Hubungan Jam Buka Pelayanan Perpustakaan dengan Minat Kunjung Pemustaka di Perpustakaan SMA Guppi Samata Gowa. Skripsi. Makassar: UIN Alauddin.

Undang-Undang Republik Indonesia Nomor 43 Tahun 2007 Tentang Perpustakaan. Jakarta.

Winoto, Y. \& Sukaesih, S. 2016. Studi Tentang Kegiatan Pengembangan Koleksi (Collection Development) pada Perpustakaan Perguruan Tinggi di Wilayah Priangan Timur Provinsi Jawa Barat. Khizanah Al-Hikmah Jurnal Ilmu Perpustakaan, Informasi, dan Kearsipan, 4(2), 118-129. 